\title{
Serebral palside omurga sorunları ve tedavi yöntemleri
}

\author{
Musculoskeletal problems and their treatment methods in cerebral palsy
}

\author{
Erhan Ulus, Muharrem Yazıcı
}

Hacettepe Üniversitesi Tıp Fakültesi Ortopedi ve Travmatoloji Anabilim Dalı, Ankara

\begin{abstract}
Serebral palsi, farklı kas iskelet sistemi problemlerine neden olabilen ve sık görülen bir statik ensefalopatidir. Periferik kas tonusunun artışıyla eklemlerde kontraktür meydana gelir ve bu durum hastanın fonksiyonel kapasitesinin azalmasıla sonuçlanır. Hastalıkta yaygın kas iskelet tutulumu olması, spinal deformite riskini arttırmaktadır. Skolyoz, bu çocuk hastalarda fonksiyonel kapasite, günlük bakım ve beslenmeyi olumsuz şekilde etkiler. Konservatif tedavi yöntemlerinden korse, fizyoterapi veya botox enjeksiyonu genellikle SP skolyozun progresyonunu durdurmaz ve cerrahi kaçınılmaz olur. Yürüyebilen beyin felçli hastalar için cerrahi hedef, daha normal bir spinal denge elde etmek, eğriliğin ilerlemesini durdurmak ve bu şekilde hastanın ambulatuvar potansiyelini korumaktır. Tekerlekli sandalyeye bağımlı hastalarda ise hedef, bağımsız oturabilme becerisini kazandırmak ve bakımı kolaylaştırmaktır. Üç boyutlu tespit imkanı sağlayan pedikül vidalarının kullanımı ile posterior enstrümantasyon ve füzyon, yeterli düzeltmenin sağlanmasında etkili olmuş, anterior cerrahi gereksinimini ortadan kaldırmıştır. Ameliyat dönemi ve ameliyat sonrası komplikasyon riski bu hastalarda yüksektir; fakat özenli ameliyat öncesi çalışma ve multidisipliner bakım ile üstesinden gelinebilir.
\end{abstract}

Anahtar sözcükler: beyin felci/komplikasyon; çocuk; lordoz/ etiyoloji; pelvis/cerrahi; rizotomi; skol-yoz/etiyoloji/cerrahi; omurga hastalığı; omurga füzyonu/enstrümantasyon
Cerebral palsy is a common static encephalopathy and can present as multiple musculoskeletal problems. Increased peripheral muscle tone causes joint contractures and decreased functional capacity. The risk for scoliosis increases parallel with the severity of musculoskeletal involvement. Scoliosis adversely affects the functional capacity, daily care, and nutrition in disabled children. Conservative treatments including physical therapy, bracing, and botulinum toxin injections do not prevent the progression of scoliosis in most of the patients, and surgical treatment becomes mandatory. The goals of surgery for the higher functioning patient are to provide a more normal spinal balance and alter the progression of disease, and to preserve function with respect to ambulatory potential; in the wheelchair-bound patient, the aim is to maintain independence in sitting and facilitate care. With the use of pedicle screws, three plane fixation is possible, making posterior instrumentation and fusion effective in correction of severe curves and obviating anterior surgery. The risk of complications, both perioperatively and postoperatively, is substantial but manageable with a careful preoperative workup, multidisciplinary care, and attention to detail.

Key words: cerebral palsy/complications; child; lordosis/ etiology; pelvis/surgery; rhizotomy; scolio-sis/etiology/surgery; spinal diseases/surgery; spinal fusion/instrumentation

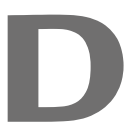

oğumdan önce, doğum sırasında ya da doğumdan sonra merkezi sinir sisteminde hasar meydana getiren hipoksi, travma, kanama veya toksik nedenler, statik ensefalopati ile sonuçlanmaktadır. Bu statik ensefalopati durumunun oluşturduğu bütün klinik tablo serebral palsi (SP) olarak tanımlanır. Problem merkezi sinir sistemindedir; fakat ortopedik açıdan, spastisite, kontraktürler, deformiteler ve yetersiz kas kontrolü gibi periferik semptomlar, tedavi ihtiyacını doğurmaktadır. Tedavide, hastalı̆̆ı bütünüyle ortadan kaldırmak yerine ikincil bulguları azaltmaya odaklanılır.

Nöromusküler bozukluk ile ilişkili olan kas imbalanSı, omurga üzerinde anormal yüklenmeye neden olur. İskeleti olgunlaşmamış bireyde kas imbalansına bağlı anormal yüklenme, vertebra cisiminin asimetrik büyümesi ile sonuçlanır. Spinal deformitenin tedavisi ve SP'li hastaların yürüyebilmesini sağlama çalışmaları, birbirinden farklı yaklaşımlar gerektirir. Omurga eğriliği statik, yürüme sorunları dinamiktir. Bunun dışında,

- İletişim adresi: Prof. Dr. Muharrem Yazıcı, Hacettepe Üniversitesi Tıp Fakültesi Ortopedi ve Travmatoloji Anabilim Dalı, Ankara Tel: 0312 - 3051209 / 122 e-posta: yazioglu@hacettepe.edu.tr

- Geliş tarihi: 1 Ekim $2018 \quad$ Kabul tarihi: 1 Ekim 2018 
yürüme sorunları için kullanılan tedavi yöntemleri daha basit ve düşük morbiditeye sahip iken, omurga deformitelerinin tedavisinde risk yüksektir ve komplikasyonlar çok sık görülür. Spinal deformitelerde tedaviye uygun hastaların belirlenmesi ve tedavi şeklinin seçimi nettir. Fakat yürüme sorunu olan hastada tedavi zamanlaması ve cerrahi planlama, karmaşık ve ayrıntılı bir değerlendirmeye intiyaç duyar.

\section{PREVALANS}

Serebral palsi hastalarında vertebra deformitesi oranı normal popülasyondan anlamlı düzeyde yüksektir. Bu oran, nörolojik defisit ciddiyetine bağlı olarak değişkenlik gösterir. Spinal deformite hemiplejik hastalarda \%5'ten az görülürken, kuadriplejik hastalarda \%70'lere varabilmektedir. Tüm SP'li hastalar arasında vertebra deformitesi sıklığı ise \%25'tir. ${ }^{[1-3]}$

\section{EĞRILIK ÖZELLIKLERi}

SP hastalarındaki spinal deformiteler, yaş, progresyon riski, eğriliğin seyri, cerrahi endikasyonu ve cerrahi olmayan tedavi yanıtı açısından idiyopatik deformitelerden farklı özelliklere sahiptir. Serebral palsi hastalarındaki deformiteler, adolesan idiyopatik skolyoza göre erken yaşta başlar ve iskelet gelişimi tamamlandıktan sonra da ilerlemeye devam eder. Bu durumda, sıklıkla cerrahiye ihtiyaç duyulur. ${ }^{[3,4]}$ On beş yaş öncesi $40^{\circ}$ 'ye ulaşmış olan eğrilikler ve pelvik oblisiteye yol açan torakolomber deformitede ilerleme riski daha yüksektir. Bununla beraber, nörolojik tutulum düzeyinin yüksek olması, skolyoz progresyonunu hızlandırır. ${ }^{[1,3]}$ SP hastaları üzerinde yapılan yakın zamanlı bir çalışmanın sonuçlarına göre, altı yaşından önce başlangıç gösteren veya 10 yaşından önce $30^{\circ}$ 'yi aşkın eğriliği olan hastalarda skolyozun daha hızlı ilerlediği belirtilmiştir. ${ }^{[4]}$

Bu hasta grubunda eğrilik daha çok torakolomber bölgede ve $C$ şeklindedir. Deformiteler genellikle rijiddir, pelvik oblisite mevcuttur ve idiyopatik skolyozdan daha yüksek açılıdır. Eğrilik tek boyutlu değildir. Koronal düzlemin yanı sıra sagittal ve aksiyel düzlemlerde de deformite vardır. İdiyopatik skolyozdan farklı olarak, apikal rotasyon ve translasyon çok ileri düzeydedir. ${ }^{[2,5]}$

\section{TEDAVIDE YAŞANAN PROBLEMLER}

İlerleyici SP skolyozu, kozmetik sorunların yanı sıra, üst ekstremitelerin günlük aktivitede kullanım alanını kısıtlar, oturma esnasında basınç noktalarında cilt problemlerine neden olur, kardiyovasküler bozukluklar ortaya çıkabilir, beslenme güçlüğü meydana getirir, aile bakımını ve taşınımı zorlaştırır. ${ }^{[2]}$ Beslenme bozukluğu sonucunda protein-enerji malnütrisyonu ve mineral dengesizliği ile bağışıklık sistemi bozulur ve enfeksiyon sıklığı artar. ${ }^{[2,6]}$

Spinal deformitenin varlığından kaynaklanan problemlere ek olarak hastalığın doğasıyla ilişkili diğer sistem sorunları tedaviyi güçleştirir. Kas iskelet kontraktürleri, kalça çıkığı, spinal deformite ile yakından ilişkili olabilir. Omurga eğriliklerinin ameliyat öncesi değerlendirilmesi sırasında kas-iskelet sistemi bütünüyle ele alınmalıdır. ${ }^{[1,2,5]}$ Azalmış mobilizasyon, yük dağılımındaki dengesizlik ve antikonvülzif tedavi ajanları, dolayısıyla osteoporoz sıktır. Pelvis normal bireylerinkinden küçüktür. Sonuçta kemik yapısındaki bu sorunlar cerrahi esnasında ve sonrasında implantla ilişkili komplikasyonların görülme sıklığını arttırır.

Hastalarda, mental gerilik ve spastisiteye ek olarak epilepsi çok sıktır. Ameliyat sonrası eksternal korse kullanımı bu nedenle mümkün değildir. Sonuç olarak, cerrahide rijid tespit ihtiyacı diğer eğriliklerden daha fazladır.

Serebral palside görülen skolyozun gelişimi için geçmişte pelvik deformiteler sorumlu tutuluyordu. Fakat artık omurga ve kalça problemleri spastisite nedeniyle ortaya çıkan birbirinden bağımsız iki antite olarak değerlendirilmektedir. Pelvik oblisite ile kalça çıkığı arasındaki ilişki birçok farklı merkezde kapsamlı şekilde araştırılmıştır. Şenaran ve ark. tarafindan yapılan bir çalışmaya göre, SP'li çocuklardaki kalça çıkı̆̆ının, skolyoz ilerlemesiyle ilişkili olmadığı gösterilmiştir. ${ }^{[7]}$ Yüksek açıda pelvik oblisitesi olup kalçası normal olan veya omurga deformitesi olmamasına rağmen tek taraflı kalça çıkı ı̆ı olan SP hastaları mevcuttur. Serebral palside kalça, yakından izlenmeli ve çıkık önlenmelidir. ${ }^{[8]}$ Bununla beraber normal kalça eklemini koruyarak spinal deformiteyi önleme fikri gerçekçi değildir.

Seçici dorsal rizotomi (SDR), spastisite tedavisi için güncel ve yaygın bir yöntemdir. ${ }^{[9,10]}$ Amaç spastisiteyi azaltarak fonksiyonel kapasiteyi arttırmaktır. Fakat posterior omurgada mekanik zayıflığa neden olması ve hiperlordoz ile spondilolistez riskini arttırması, yöntemi omurga cerrahları için tartışmalı hale getirmektedir. SDR sonrası meydana gelen mekanik instabilite, posterior kaslarda ve kalça fleksörlerinde ortaya çıkan zayıflık, spinal deformite için riski arttırır. Seçici dorsal rizotomi uygulanmış bir olgu serisinde, SDR'den sonra skolyoz gelişme oranının \%36 olduğu belirtilmiştir. Bu oran, cerrahi dışı yöntemlerle tedavi edilen SP hastalarını kapsayan gruba göre daha yüksektir. ${ }^{[11]}$ Uygun endikasyonlar ile doğru hasta seçerek uygulandığında, SDR ameliyatı SP'li hastaların yürüme becerilerini ciddi oranda arttırmaktadır Bu nedenle, spinal deformite 
tedavisine göre daha komplike olan yürüme sorunlarının tedavisinde, seçici dorsal rizotomi, hastaların ambulatuvar kapasitesini arttırmak açısından dikkate değer bir yöntemdir. ${ }^{[9,10]}$

İntratekal baklofen pompası (iTB), spastisite tedavisi için başka bir seçenektir. Bu yöntemle, intratekal bölgeye baklofen verilmesini sağlayan bir cilt altı pompa yerleştirilir. Spastisitenin tedavi ile önemli ölçüde azaltılabildiği ve erken dönemde uygulandığında motor gelişimde düzelme olduğu gösterilmiştir. ${ }^{[12]}$ Paravertebral kaslarda bu tedavi sonrası spastisitenin azalması ile skolyoz seyrinin nasıl değişeceği tartışmalıdır. Bir çalışmada, intratekal baklofen tedavisi almamış spastik SP'li kontrol grubuyla karşılaştırıldığında, intratekal baklofenin eğrilik ilerlemesi, pelvik oblisite veya skolyoz sıklığında anlamlı bir etkisi olmadığı gösterilmiştir. ${ }^{[13]}$ Benzer sonuçlara sahip başka seriler de yayımlanmıştır. ${ }^{[14,15]}$ Intratekal baklofen uygulaması ile ilgili güncel bir çalışmaya göre ITB uygulanan SP hastalarında, kontrol grubuna göre yeni deformite gelişimi açısından anlamlı fark olmamakla birlikte, var olan skolyozun progresyonunun daha fazla olduğu gösterilmiş, bu nedenle ITB tedavisi sonrası hastaların deformitesinin yakından izlenmesi gerektiği belirtilmiştir. ${ }^{[16]}$

\section{CERRAHI DIŞI TEDAVI}

SP skolyoz hastalarında korse kullanımı deformite progresyonunu genellikle engelleyemez. ${ }^{[17-19]} \mathrm{Bu}$ hastaların zaten korse kullanımına uyum göstermeleri çok zordur Ayrıca, korse içindeyken olası bir epileptik nöbet kötü sonuçlara yol açabilir; aynı şekilde, korse kullanımı, göğüs duvarı hareketlerinde kısıtlılığa ve dolayısıyla da var olan pulmoner sorunların şiddetlenmesine neden olabilir. Basınç yaralarının bu hastalarda daha sık görülmesi de korse tedavisinin önündeki engellerdendir.

Omurga eğriliğiyle beraber spastisitenin tedavisinde botulinum toksin (botoks) kullanımı ile ilgili kayda değer düzeyde az sayıda çalışma olmasına rağmen, ilk sonuçlar umut vadetmekteydi. Nuzzo ve ark. tarafindan yapılan bir çalışmada ${ }^{[20]}$, deformitenin konkav tarafina botoks enjeksiyonunun, korse tedavisi ile kombine edildiğinde, eğriliğin progresyonunu durdurduğu bildirilmişti. Fakat Wong ve ark.'nın ${ }^{[21]}$ yayımladığı yakın zamanlı bir çalışma sonrası, bu tedavi hakkında ciddi tereddütler ortaya çıkmıştır. Bu çalışma, SP hastalarında skolyoz tedavisi için paraspinal kaslara botoks veya plasebo enjeksiyonu yapılan iki grubun kıyaslandığı bir çalışmaydı. Çalışma sürerken, hastalardan birinde pnömoni ile sonuçlanan ciddi bir yan etki gelişmiş ve hastanın ölümüyle sonuçlanmıştır. Üstelik diğer hastaların verileri takiplerde değerlendirildiğinde, botoks enjeksiyonu yapılan grup ile kontrol grubu arasında anlamlı bir fark bulunamamıştır. ${ }^{[21]}$

Non-ambulatuvar SP hastalarında tekerlekli sandalye modifikasyonları; dik oturuş pozisyonu sağlamak, üst ekstremitelerin serbest kullanımı ve bakımını kolaylaştırmak, beslenme zorluklarını yenmek açısından değerlidir. ${ }^{[22]}$ Bilgisayar destekli üç boyutlu kişiye özel tekerlekli sandalye teknolojisi ile, özellikle bası yaralarının önüne geçilebildiği rapor edilmiştir. Fakat bu şekilde omurga deformitesinin ilerlemesini kontrol etmek mümkün değildir.

\section{CERRAHI ENDIKASYONLARI}

Cerrahi kararını vermede deformitenin ilerlemesi ve fonksiyonel kayıpların oluşması en önemli iki parametredir. Spastik kuadriplejik hastalar skolyoz sıklığının en yüksek olduğu gruptur. ${ }^{[3]}$ Bu hasta grubunun \%70'inde iskelet olgunlaşmasından sonra ilerlemeye devam eden skolyoz vardır. Saito ve ark. $.^{[3]}, 15$ yaş öncesi $40^{\circ}$ 'den büyük eğriliği olan hastalarda yaş ile deformitenin artmaya devam etme olasılığının yüksek olduğunu gösteren bir çalışma yayımlamış ve bu hastalar için cerrahi önermişlerdir. Cerrahi tedavide en büyük fonksiyonel kazanım, oturma dengesinin sağlanması ve hastanın üst ekstremitelerinin özgürleştirilmesidir. Diğer olumlu etkiler ise, pulmoner kapasitenin korunması ve beslenmede kolaylıktır. Spinal dizilimin düzelmesiyle, bu hastalarda hiperlordozun neden olduğu gastro-özofageal reflü ve superior mezenterik arter sendromu gibi problemlerde de olumlu sonuçlar alınabilir. ${ }^{[23,24]}$

\section{CERRAHININ AVANTAJ VE DEZAVANTAJLARI}

Serebral palside cerrahi tedavi zor ve pahalı bir süreçtir. Ameliyattan sonra değerli sonuçlar elde edilebilmesine rağmen, hastalığın doğası, fonksiyonel iyileşmeyi kısıtlı tutmaktadır. Skolyozu bulunan ancak mental geriliği olmayan hemiplejik veya diplejik hastalarda cerrahi uygulanması konusunda yaygın uzlaşı mevcuttur (Şekil 1). Fakat, spastik kuadriplejik hastalarda cerrahi endikasyonlar tartışmalıdır. ${ }^{[1,25]}$ Bu hasta grubu için cerrahinin maliyet-yarar oranı etik açıdan yoğun bir şekilde tartışılmaktadır. Cerrahiyi uygulayan ekibin deneyimli olması ve tedavinin büyük bir merkezde yapılması koşuluyla hastaların kalan yaşam süreleri uzatılamasa bile, omurga deformitesinin düzeltilmesi hayat kalitesine pozitif etki edebilmektedir. Aileler hastaların yaşam kalitesinde anlamlı değişiklikler bildirmiş, düzeltici omurga ameliyatlarından sonra daha mutlu olduklarını belirtmişlerdir. ${ }^{[12,26-28]}$ Yakın zamanda, Miyanji ve ark. tarafından yayımlanan kapsamlı bir çalışmada, cerrahi sonrası yaşam kalitesindeki artışın 


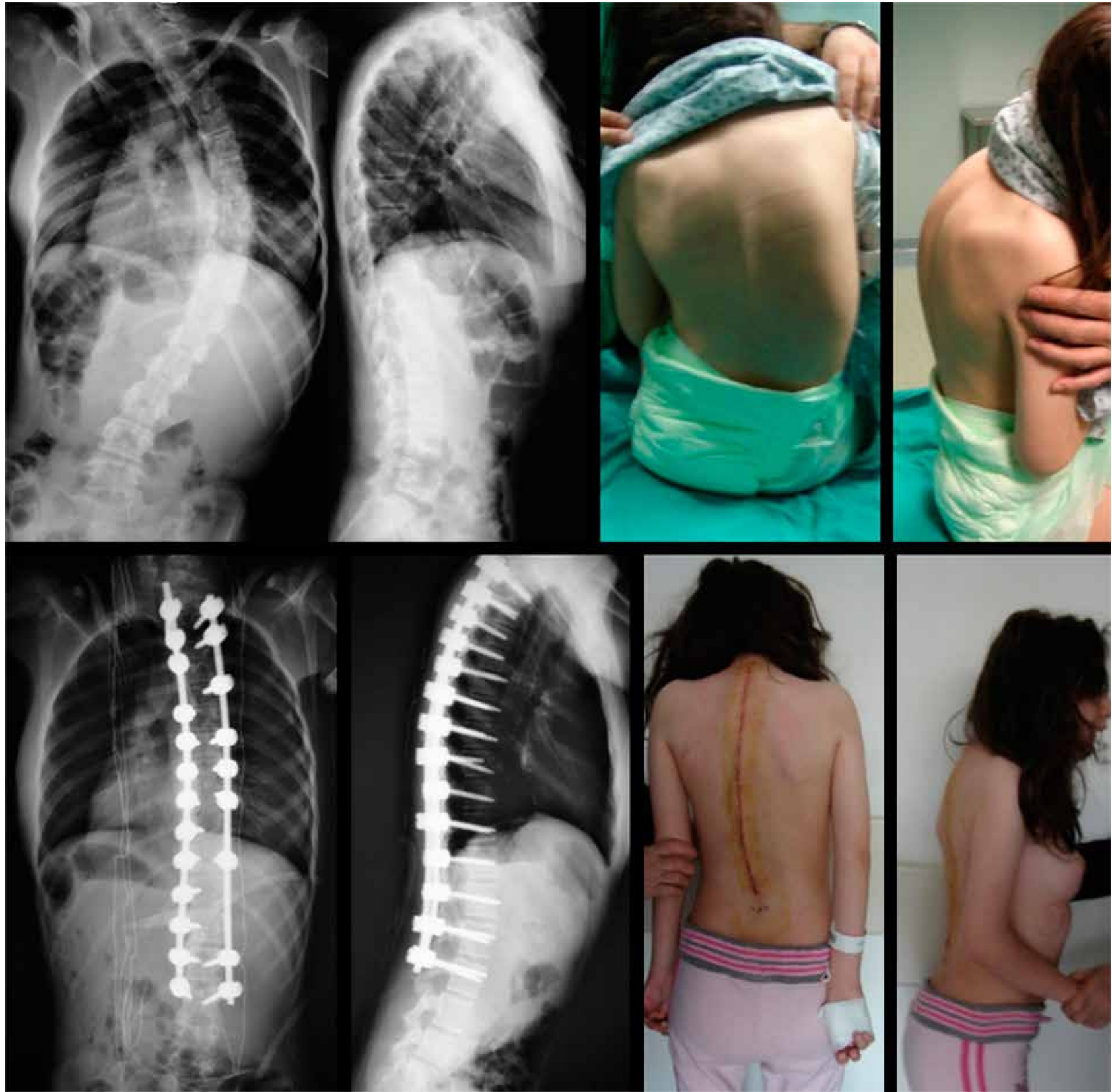

Şekil 1. On sekiz yaşında, kaba motor fonksiyon sınıflandırma sistemi (GMFSC)'ne göre ikinci seviye kız hasta. Bağımsız yürüyebilen hastanın idiyopatik skolyoz özellikleri taşıyan eğriliği, idiyopatik skolyoz gibi tedavi edildi.

komplikasyon riskine kıyasla belirgin şekilde fazla olduğu gösterilmiştir. ${ }^{[29]}$ Çoğu SP hastasında mental ve fiziksel ciddi engeller bulunmasına rağmen, bu hastalar iyi bir bakımdan yarar sağlayabilecek durumdadır. Bu nedenle hastayı tıbbın son imkanlarından mahrum etmek, doktorların sorumluluğunda olmamalıdır.

Cerrahi endikasyona sahip hastalarda, eğrilik henüz ilerlememiş ve rijid hale gelmemişken yapılabilecek erken girişim ile başarı oranı artar ve olası ameliyat sonrası komplikasyonlar azaltılmış olur.

\section{CERRAHI TEKNIKLER}

Kullanılan cerrahi enstrümanlar, deformiteyi üç boyutlu olarak düzeltme amacına uygun olmalıdır. Ameliyat sonrasında dış destek ihtiyacını ortadan kaldıracak kadar güçlü ve bu hasta grubunda omurga 


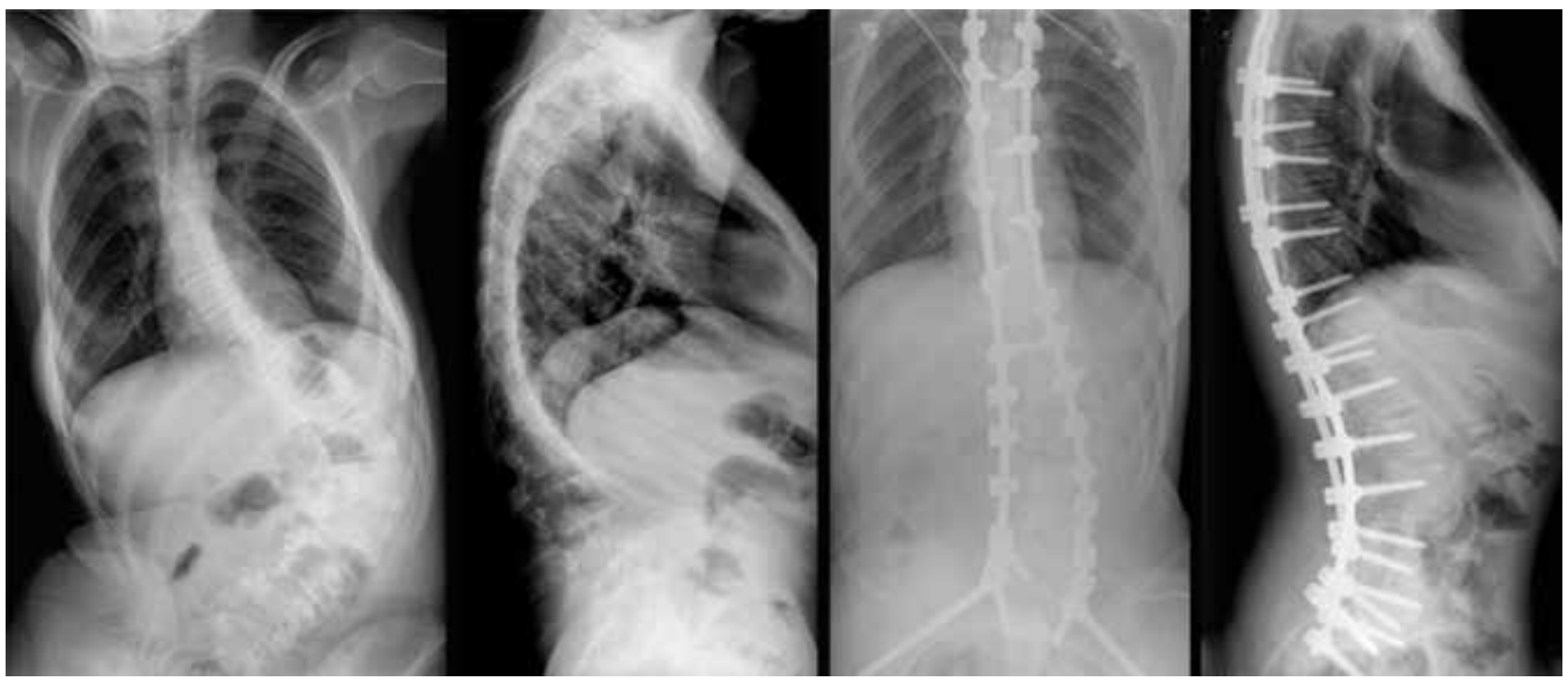

Şekil 2. On dört yaşında, kaba motor fonksiyon sınıflandırma sistemi (GMFSC)'ne göre beşinci seviye erkek çocuk. Oturma dengesini bozan, kosto-pelvik sıkışma nedeniyle ciddi ağılara neden olan eğrilik, sadece posterior enstrümantasyon ve füzyon ile tedavi edildi.

çevresindeki kaslar atrofik olduğu için, düşük profilli tasarlanmış olmalıdır. ${ }^{[24]}$ Enstrümantasyona her zaman füzyon desteği eklenmeli, füzyon, üst torakal vertebralardan pelvise kadar uzanmalıdır.[2,24,30] Geçmişte, pelvik tespitin yürüme kapasitesini azalttığı düşünülmekteydi. Bu nedenle, ambulatuvar hemiplejik hastalarda füzyonun pelvise kadar uzatılması konusunda ciddi endişeler vardı. Günümüzde bu kaygılar son bulmuştur. Sagittal düzlemde kontürlerin uygun şekilde restorasyonu sonucunda, ambulatuvar hastaların yürüme becerisinde değişiklik olmadığı artık bilinmektedir. ${ }^{[24,30-32]}$ Daha önceki dönemde pelvik tespit sonucu ortaya çıkan yürüme becerisindeki kayıp sorunları, artık füzyondan kaynaklanmamaktadır. Burada asıl sorun, lordozun düzeltilememesi ve çok uzun süre immobilizasyondur. ${ }^{[2,31]}$

Pedikül vidaları ile üç boyutlu tespit sağlanarak daha büyük rotasyonel kuvvet uygulanır. Bu rotasyonel kuvvetler deformite koreksiyonu için çok değerlidir. Ayrıca, pedikül vidalarının; eski teknikler olan sublaminar teller ve $L$ rodlarına göre, posterior füzyon elde etmek konusunda çok daha başarılı olduğu kanıtlanmıştır. Serebral palsi hastalarında, implantın kemikten geri çıkma riski osteoporoz nedeniyle yüksektir; bu açıdan, enstrümantasyon esnasında mümkün olduğunca büyük çaplı vidalar tercih edilmelidir. Vidalar mümkünse enstrümante edilecek alandaki her seviyeye konulmalıdır. Füzyonu sağlayabilmek için genellikle allogreft kullanımı tavsiye edilmektedir. ${ }^{[23,33]}$
Bazı yazarlar, posterior füzyon yapılacak genç hastalarda "crankshaft fenomeni" gelişimini engellemek amacıyla anterior girişim yapılması gerektiğini savunmaktadır. Bununla beraber, SP hastalarında crankshaft fenomeninin çok sık karşılaşılan bir sorun olmadığı bilinmektedir. Smucker ve Miller ${ }^{[8]}$ SP skolyoz hastalarında crankshaft fenomeninin tedavide belirleyici bir sorun olmadığını ve ortaya çıkma ihtimalinin düşük olduğunu belirtmiş olsalar da, bu olasılık tamamen dışlanamaz. Çünkü, serilerde 10 yaş öncesi ameliyat edilen ve erişkinliğe kadar takibi yapılan hasta sayısı oldukça azdır.

Skolyozda spinal deformite nedenli akciğer kapasitesinde meydana gelen azalma, anterior girişim ile birlikte solunum sıkıntısı riskini daha da arttırmaktadır. Serebral palsi hastalarında posterior yaklaşımla, daha önce bahsedildiği gibi, anterior girişim ihtiyacını doğuran crankshaft fenomeni gelişmesini engelleyecek şekilde, tatmin edici üç boyutlu koreksiyon sağlanabilmektedir.

Enstrümantasyonda asıl hedef, pelvik oblisiteyi düzelterek başı pelvis ile aynı hat üzerinde konumlandırmaktır. ${ }^{[23]}$ Hastanın sagittal plandaki eğriliğini düzeltmek ve yeni pozisyonu muhafaza etmek, her zaman koronal plandaki düzeltmeden daha zordur. Hiperlordoz veya hiperkifozun yalnızca sublaminar teller veya hook'lar aracılığıyla düzeltilmesi, pedikül vidalarının kullanıma girmesinden önce hiç kolay değildi. Günümüzde vidalar ile sagittal plan problemlerinin de üstesinden gelindiği söylenebilir (Şekil 2). ${ }^{[24,31]}$ 


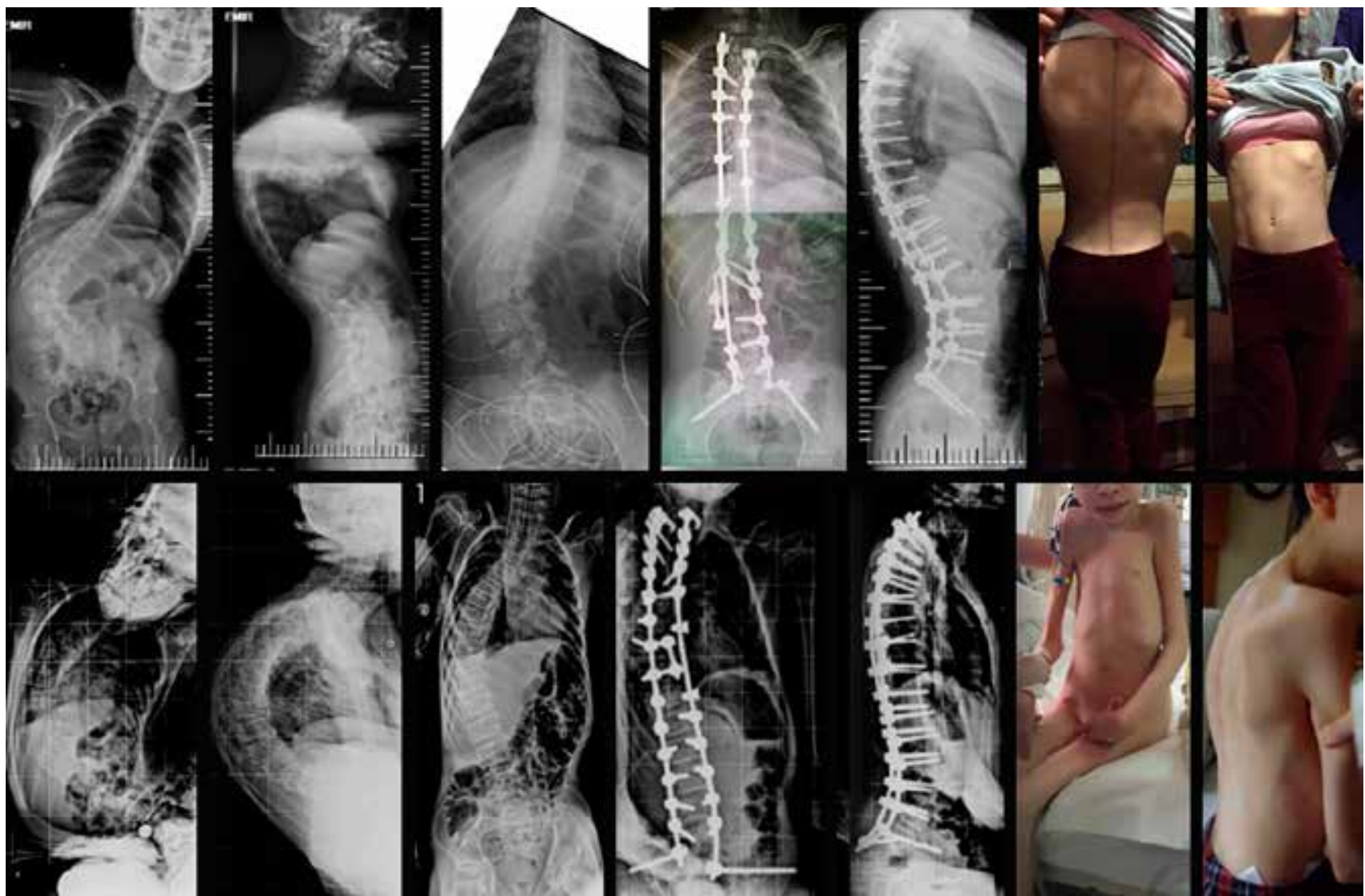

Şekil 3. Üstte GMFSC 4, 16 yaşında kız çocuğu; altta GMFSC 5, 18 yaşında erkek çocuğuna ait grafiler. Her iki hastanın da son derece rijid eğrilikleri, posteriordan apeks vertebraya uygulanan pedikül çıkartma osteotomisi sonrası posterior enstrümantasyon ve füzyon ile düzeltildi. Anterior gevşetme veya halo traksiyon uygulanmadan, sadece posterior yaklaşımla, tek seansta yeterli düzeltme elde edilebildi.

SP skolyozunda pelvik tespit, non-ambulatuvar ve pelvik oblisitesi olan hastalarda oturma dengesinin oluşturulması için uygulanır. Pelvik oblisite $15^{\circ}$ den az ise önerilmemektedir. Sakral-alar-iliak vidalar bazı avantajları nedeniyle son zamanlarda pediatrik hastalarda öne çıkan bir pelvik tespit metodudur. Bu vidalar için giriş noktası olarak S1 dorsal foramenin $1 \mathrm{~mm}$ kaudali ve $1 \mathrm{~mm}$ distali kullanılmaktadır. Bu giriş noktaları lumbar pedikül vidaları ile aynı hizada olduğu için konnektör kullanım gereksinimini elemine etmektedir. Vida giriş noktaları Galveston tekniği ve iliak vidalarınkinden farklı olarak, cilt irritasyonu yaratan implant kabarıklığına neden olmamakta; ayrıca, önceki tekniklerden farklı olarak ayrı bir fasyal kesiye ihtiyaç duyulmamaktadır. ${ }^{[34]}$

Bir süre öncesine kadar, yeterli düzelme ve etkin füzyon için anterior girişimin, bazı olgularda gerekli olabileceği düşünülürdü. ${ }^{24,35,36]}$ Fakat, etkin deformite düzeltmesi için artık bu görüş geçerliliğini yitirmiştir.
Bekmez ve ark. ${ }^{[37]}$ tarafından yapılan yakın zamanlı çalışmaya göre, nöromusküler skolyoz hastalarında posterior yaklaşımlı osteotomilerin deformite düzeltilmesinde yeterli olduğu belirtilmiştir. Bu çalışmada hastalar iki gruba ayırılıp, bir gruba pedikül subtraction osteotomi (PSO) ve diğer gruba da çoklu posterior kolon osteotomileri (PCO) uygulanmıştır. PSO uygulanan grupta ortalama $66,7^{\circ}$, çoklu PCO uygulanan grupta ise $56,1^{\circ}$ düzeltme sağlanmıştır. Bu düzeltme oranları, yazarlar tarafindan tatmin edici olarak değerlendirilmiş ve anterior gevşetme ihtiyacının bulunmadığı belirtilmiştir (Şekil 3).

\section{KOMPLIKASYONLAR}

Ameliyat öncesi ve sonrası malnütrisyondan kaçınılmalıdır. Bu açıdan, diyetisyen desteği önemlidir. Bunun yanı sıra akciğer kapasitesi dikkatli şekilde tetkik edilmelidir. Üst ve alt solunum yolu enfeksiyonları, 
atelektazi gibi solunum kapasitesini azaltan etkenler tedavi edilmelidir. ${ }^{[6]}$

Yetkin bir anestezi ekibinin varlı̆̆ı önemlidir. Olası bir mekanik ventilasyon ihtiyacı için hazırlıklı olunmalıdır. SP hastalarında çeşitli nedenlerle koagülasyon bozuklukları sıktır ve ameliyatta kan kaybının fazla olması beklenir ${ }^{[38]}$; bu durum valproik asit kullanımı olan hastalarda daha da sıktır. Bunun yanı sıra, akut rehidrasyon nedenli dilüsyon fenomeni için her zaman uyanık olunmalıdır. Ameliyatta kan kaybı yüksek oranda venöz sistemden meydana gelir; bu nedenle, hipotansif anestezi ile kanama engellenemez.

Cerrahi nedenli nörolojik defisit sık görülmez. Bununla beraber, nörolojik defisit riskini bertaraf etmek için nöromonitorizasyon kullanımı bu hasta grubu için hala tartışmalıdır. Çünkü yapılan çalışmalarda, nöromusküler skolyoz hastalarında nöromonitorizasyonun yüksek yalancı negatif veya pozitif sonuçlara sahip olduğu bildirilmiştir. Yine, yürüyemeyen ve alt ekstremitelerini fonksiyonel kullanamayan hastalarda oluşacak motor defisitin çok da önemli olmadığı söylenmektedir. Buna rağmen, özellikle zekâ geriliği olmayan hastalarda, mesane ve barsak sfinkter fonksiyonlarının korunması, ayrıca duyusal defisitin önlenmesi çok önemlidir. Tüm sorunlara rağmen, cerrahların büyük çoğunluğu nöromonitorizasyon kullanımı konusunda ısrarcı davranmaktadır.

Ameliyattan sonra enfeksiyon oranları, diğer skolyoz tiplerine göre SP hastalarında yüksektir. ${ }^{[6,39,40]}$ Zekâ geriliği, allogreft kullanımı, epilepsi, serum protein düzeyi düşüklüğü ve lökopeni gibi durumlar enfeksiyon riskini yükseltir. Ancak, son yıllarda bu konudaki yaklaşımlarda da önemli değişiklikler olmuş, iyi değerlendirme ve bazı tedbirlerle oranın ciddi düzeyde azaltılabildiği gösterilmiştir. Jain ve ark. tarafından yapılan bir çalışmada, spinal füzyonu takiben derin doku enfeksiyonu meydana gelen SP hastalarında debridman ve altı haftalık antibiyotik tedavisi sonrası tekrarlayıcı enfeksiyon oranının yüksek olmadığı, hatta sonraki süreçte enfeksiyon gelişme riskinin hiç enfekte olmamış spinal füzyon hastaları ile aynı olduğu belirtilmiştir. ${ }^{\left[{ }^{[1]}\right.} \mathrm{Bu}$ ve benzeri ümit verici çalışmalar, SP’li skolyoz hastalarıyla ilgili eski korkuları büyük ölçüde azaltmıştır.

\section{SONUÇ}

Serebral palside spinal deformite, hastalığın tutulum derecesiyle artış göstermektedir. Eğrilikteki ilerleme iskelet matürasyonu ile sona ermez ve bu açıdan idiyopatik skolyozdan farklıdır. Büyük deformiteler fonksiyonel kapasitede azalmaya, oturma dengesizliğine ve basınç bölgelerinde cilt problemlerine neden olur, solunum ve dolaşımı kötü etkiler. Konservatif tedaviyle deformitenin ilerlemesi durdurulamamaktadır. Bu nedenle, çoğu hastaya posterior yaklaşımlı enstrümantasyon ve füzyon gerekir. Pedikül vidalarının kullanımıyla, deformite üç planlı olarak düzeltilebilir ve anterior girişime ihtiyaç duyulmaz. Pelvik oblisitesi olan hastalarda enstrümantasyon, sakrumu da içine alacak şekilde distale uzatılmalıdır. İyi değerlendirme ve titiz tekniklerle, komplikasyon oranları makul seviyelere indirilebilir. Başarılı bir omurga cerrahisinden sonra, hasta, aile ve bakıcı memnuniyeti çok yüksektir.

\section{KAYNAKLAR}

1. Majd ME, Muldowny DS, Holt RT. Natural history of scoliosis in the institutionalized adult cerebral palsy population. Spine 1997;22(13):1461-6. Crossref

2. McCarthy RE. Management of neuromuscular scoliosis. Orthop Clin North Am 1999;30(3):435-49. Crossref

3. Saito N, Ebara S, Ohotsuka K, Kumeta H, Takaoka K. Natural history of scoliosis in spastic cerebral palsy. Lancet 1998;351(9117):1687-92. Crossref

4. Yoshida K, Kajiura I, Suzuki T, Kawabata H. Natural history of scoliosis in cerebral palsy and risk factors for progression of scoliosis. J Orthop Sci 2018;23(4):649-52. Crossref

5. Aronsson DD, Stokes IA, Ronchetti PJ, Labelle HB. Comparison of curve shape between children with cerebral palsy, Friedreich's ataxia, and adolescent idiopathic scoliosis. Dev Med Child Neurol 1994;36(5):412-8. Crossref

6. Jevsevar DS, Karlin LI. The relationship between preoperative nutritional status and complications after an operation for scoliosis in patients who have cerebral palsy. J Bone Joint Surg 1993;75(6):880-4. Crossref

7. Şenaran H, Shah SA, Glutting JJ, Dabney KW, Miller F. The associated effects of untreated unilateral hip dislocation in cerebral palsy scoliosis. J Pediatr Orthop 2006;26(6):769-72. Crossref

8. Smucker JD, Miller F. Crankshaft effect after posterior spinal fusion and unit rod instrumentation in children with cerebral palsy. J Pediatr Orthop 2001;21(1):108-12. Crossref

9. Johnson MB, Goldstein L, Thomas SS, Piatt J, Aiona M, Sussman M. Spinal deformity after selective dorsal rhizotomy in ambulatory patients with cerebral palsy. J Pediatr Orthop 2004;24(5):529-36. Crossref

10. Spiegel DA, Loder RT, Alley KA, Rowley S, Gutknecht S, Smith-Wright DL, Dunn ME. Spinal deformity following selective dorsal rhizotomy. J Pediatr Orthop 2004;24(1):306. Crossref

11. Turi $M$, Kalen $V$. The risk of spinal deformity after selective dorsal rhizotomy. J Pediatr Orthop 2000;20(1):104-7. Crossref

12. Gooch JL, Oberg WA, Grams B, Ward LA, Walker ML. Care provider assessment of intrathecal baclofen in children. Dev Med Child Neurol 2004;46(8):548-52. Crossref

13. Şenaran H, Shah SA, Presedo A, Dabney KW, Glutting JW, Miller F. The risk of progression of scoliosis in cerebral palsy patients after intrathecal baclofen therapy. Spine 2007;32(21):2348-54. Crossref

14. Ginsburg GM, Lauder AJ. Progression of scoliosis in patients with spastic quadriplegia after the insertion of an intrathecal baclofen pump. Spine 2007;32(24):2745-50. Crossref 
15. Shilt JS, Lai LP, Cabrera MN, Frino J, Smith BP. The impact of intrathecal baclofen on the natural history of scoliosis in cerebral palsy. J Pediatr Orthop 2008;28(6):684-7. Crossref

16. Walker KR, Novotny SA, Krach LE. Does Intrathecal Baclofen Therapy Increase Prevalence and/or Progression of Neuromuscular Scoliosis? Spine Deform 2017;5(6):424-9. Crossref

17. Leopando MT, Moussavi Z, Holbrow J, Chernick V, Pasterkamp H, Rempel G. Effect of a Soft Boston Orthosis on pulmonary mechanics in severe cerebral palsy. Pediatr Pulmonol 1999;28(1):53-8. Crossref

18. Terjesen $\mathrm{T}$, Lange JE, Steen $\mathrm{H}$. Treatment of scoliosis with spinal bracing in quadriplegic cerebral palsy. Dev Med Child Neurol 2000;42(7):448-54. Crossref

19. Miller A, Temple T, Miller F. Impact of orthoses on the rate of scoliosis progression in children with cerebral palsy. J Pediatr Orthop 1996;16(3):332-5. Crossref

20. Nuzzo RM, Walsh S, Boucherit T, Massood S. Counterparalysis for treatment of paralytic scoliosis with botulinum toxin type A. Am J Orthop 1997;26(3):201-7.

21. Wong C, Pedersen SA, Kristensen BB, Gosvig K, SonneHolm S. The Effect of Botulinum Toxin A Injections in the Spine Muscles for Cerebral Palsy Scoliosis, Examined in a Prospective, Randomized Triple-blinded Study. Spine (Phila Pa 1976) 2015;40(23):E1205-11. Crossref

22. Holmes KJ, Michael SM, Thorpe SL, Solomonidis SE. Management of scoliosis with special seating for the nonambulant spastic cerebral palsy population -a biomechanical study. Clin Biomech 2003;18(6):480-7. Crossref

23. Huang MJ, Lenke LG. Scoliosis and severe pelvic obliquity in a patient with cerebral palsy: surgical treatment utilizing halofemoral traction. Spine 2001;26(19):2168-70. Crossref

24. Yazıcı M, Asher MA, Hardacker JW. The safety and efficacy of Isola-Galveston instrumentation and arthrodesis in the treatment of neuromuscular spinal deformities. J Bone Joint Surg Am 2000;82(4):524-43. Crossref

25. Tsirikos Al, Chang WN, Dabney KW, Miller F, Glutting J. Life expectancy in pediatric patients with cerebral palsy and neuromuscular scoliosis who underwent spinal fusion. Dev Med Child Neurol 2003;45(10):677-82.

26. Comstock CP, Leach J, Wenger DR. Scoliosis in total-body involvement cerebral palsy. Analysis of surgical treatment and patient and caregiver satisfaction. Spine 1998;23(12):141224. Crossref

27. Jones KB, Sponseller PD, Shindle MK, McCarthy ML. Longitudinal parental perceptions of spinal fusion for neuromuscular spine deformity in patients with totally involved cerebral palsy. J Pediatr Orthop 2003;23(2):143-9. Crossref

28. Tsirikos Al, Chang WN, Dabney KW, Miller F. Comparison of parents' and caregivers' satisfaction after spinal fusion in children with cerebral palsy. J Pediatr Orthop 2004;24(1):548. Crossref
29. Miyanji F, Nasto LA, Sponseller PD, Shah SA, Samdani AF, Lonner B, Yaszay B, Clements DH, Narayanan U, Newton PO. Assessing the Risk-Benefit Ratio of Scoliosis Surgery in Cerebral Palsy: Surgery is worth it. J Bone Joint Surg Am 2018;100(7):556-63. Crossref

30. Lipton GE, Letonoff EJ, Dabney KW, Miller F, McCarthy HC. Correction of sagittal plane spinal deformities with unit rod instrumentation in children with cerebral palsy. J Bone Joint Surg Am 2003;85(12):2349-57. Crossref

31. Sink EL, Newton PO, Mubarak SJ, Wenger DR. Maintenance of sagittal plane alignment after surgical correction of spinal deformity in patients with cerebral palsy. Spine 2003;28(13):1396-403. Crossref

32. Tsirikos Al, Chang WN, Shah SA, Dabney KW, Miller F. Preserving ambulatory potential in pediatric patients with cerebral palsy who undergo spinal fusion using unit rod instrumentation. Spine 2003;28(5):480-3. Crossref

33. Yazıcı M, Asher MA. Freeze-dried allograft for posterior spinal fusion in patients with neuromuscular spinal deformities. Spine 1997;22(13):1467-71. Crossref

34. Jain A, Sullivan BT, Kuwabara A, Kebaish KM, Sponseller PD. Sacral-Alar-lliac Fixation in Children with Neuromuscular Scoliosis: Minimum 5-Year Follow-Up. World Neurosurg 2017;108:474-8. Crossref

35. Sarwahi V, Sarwark JF, Schafer MF, Backer C, Lee M, King EC, Aminian A, Grayhack JJ. Standards in anterior spine surgery in pediatric patients with neuromuscular scoliosis. J Pediatr Orthop 2001;21(6):756-60. Crossref

36. Tsirikos Al, Chang WN, Dabney KW, Miller F. Comparison of one-stage versus two-stage anteroposterior spinal fusion in pediatric patients with cerebral palsy and neuro-muscular scoliosis. Spine 2003;28(12):1300-5. Crossref

37. Bekmez S, Ozhan M, Olgun ZD, Suzer A, Ayvaz M, Demirkiran HG, Karaagaoglu E, Yazici M. Pedicle Subtraction Osteotomy Versus Multiple Posterior Column Osteotomies in Severe and Rigid Neuromuscular Scoliosis. Spine (Phila Pa 1976) 2018;43(15):E905-10. Crossref

38. Brenn BR, Theroux MC, Dabney KW, Miller F. Clotting parameters and thromboelastography in children with neuromuscular and idiopathic scoliosis undergoing posterior spinal fusion. Spine 2004;29(15):E310-4. Crossref

39. Sponseller PD, LaPorte DM, Hungerford MW, Eck K, Bridwell $\mathrm{KH}$, Lenke LG. Deep wound infections after neuromuscular scoliosis surgery: a multicenter study of risk factors and treatment outcomes. Spine 2000;25(19):2461-6. Crossref

40. Szöke G, Lipton G, Miller F, Dabney K. Wound infection after spinal fusion in children with cerebral palsy. J Pediatr Orthop 1998;18(6):727-33. Crossref

41. Jain A, Modhia UM, Njoku DB, Shah SA, Newton PO, Marks MC, Bastrom TP, Miyanji F, Sponseller PD. Recurrence of Deep Surgical Site Infection in Cerebral Palsy After Spinal Fusion Is Rare. Spine Deform 2017;5(3):208-12. Crossref 